\title{
SPECIAL REPORT
}

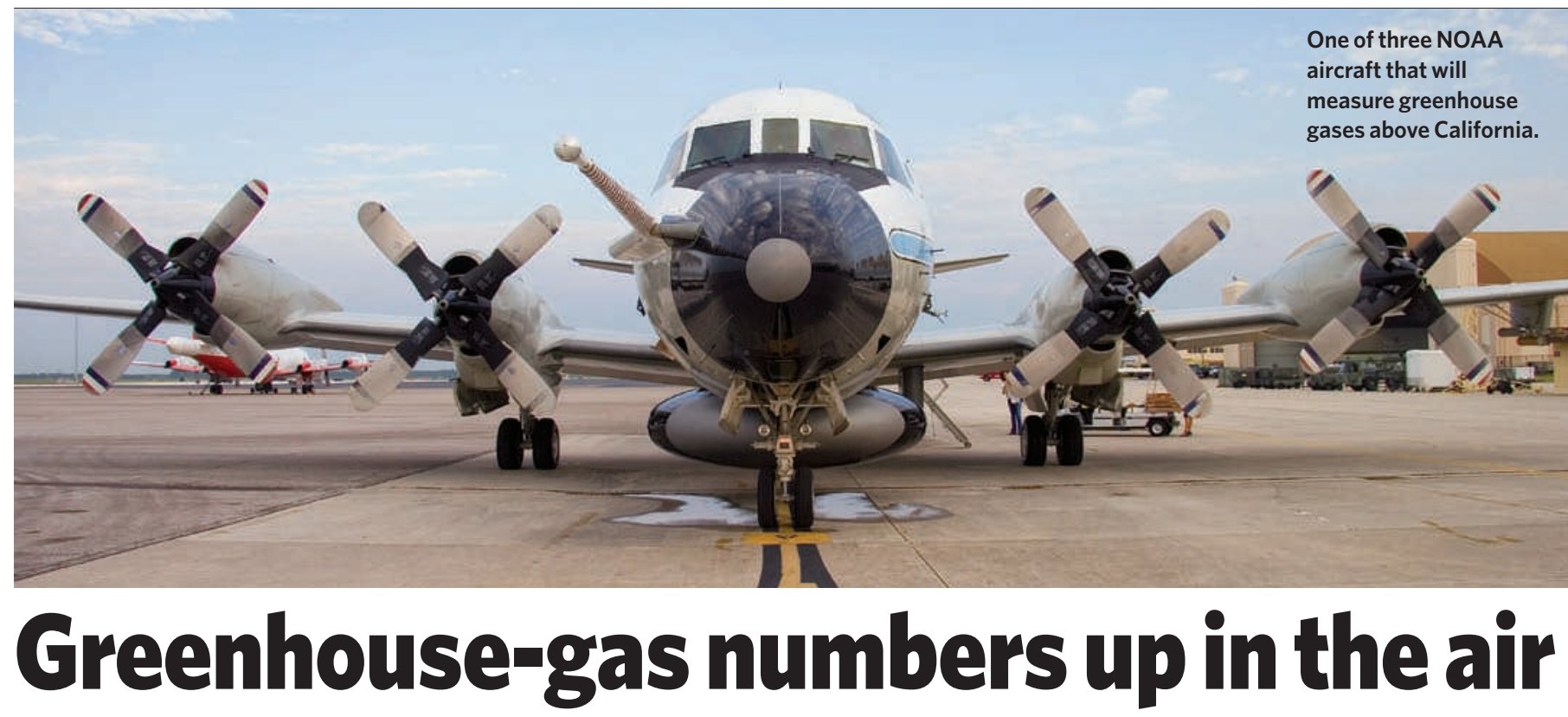

\section{To control emissions, countries must first account accurately for their carbon. That will take considerable effort, reports Jeff Tollefson.}

The state of California is about to become a giant playground for more than 200 atmospheric scientists. Beginning this week and extending into July, aircraft will criss-cross the skies, measuring an array of greenhouse gases, aerosols and other atmospheric properties as they fly over cities, industrial facilities and agricultural areas. Dozens of scientists will man two ground stations, while a ship monitors the air off the coast and two electric vehicles zip about collecting samples upwind and downwind of selected sites.

Organized by the California Air Resources Board and the National Oceanic and Atmospheric Administration (NOAA) in Boulder, Colorado, the 'CalNex' campaign is designed to take a detailed snapshot of the air above California. Scientists plan to study a host of issues relating to air quality and global warming, but one of the primary goals will be to plug holes and reduce nagging uncertainties in the state's two-year-old inventory of greenhouse-gas emissions.

Much depends on the veracity of those numbers, including the state's commitment to reduce such emissions to $80 \%$ below 1990 levels by mid-century. And the challenge is not unique to California. Developed countries that are party to the United Nations Framework Convention on Climate Change (UNFCCC) are required to report inventories of their yearly greenhousegas emissions. Yet those numbers are riddled with uncertainties, and independent estimates suggest that the total reported emissions for some gases may be off by more than $50 \%$. If a future global-warming treaty is to have any credibility, scientists and governments need to develop a reliable system for verifying greenhouse-gas emissions around the globe.

"Countries have a tendency to always report a little bit less because it looks good, and nobody can prove that they are wrong unless we go to the atmosphere," says Ingeborg Levin, an atmospheric physicist at the University of Heidelberg in Germany.

Levin is one of many scientists developing air-sampling networks, computer models and satellites to assess the origin and amount of greenhouse-gas emissions. She sees the California programme as a model and says that governments need to begin working with scientists to reduce uncertainties in their emissions inventories. "It is extremely difficult to do this accurately," she says. "It must be a concerted effort between the people who do the inventories and the people who do the measurements."

In March, the US National Research Council (NRC) weighed in, calling for more detailed inventories from industrialized countries and an expansion and improvement of greenhousegas monitoring networks everywhere. The NRC estimated that it would cost just US $\$ 11$ million over five years to improve greenhousegas reporting systems among the 10 largest developing countries, which are not currently required to report their annual emissions to the United Nations climate framework. In principle, these countries agreed to additional reporting requirements as part of the Copenhagen climate accord signed in December, but developing and developed nations are still negotiating how to structure a verification system.

\section{Finding all the carbon}

Much of the current focus is on emissions from fossil fuels, which account for more than half of the global greenhouse gases pumped into the atmosphere annually, and are the easiest to quantify. Essentially all of the carbon in fossil fuels winds up in the atmosphere as carbon dioxide after combustion, and so carbon dioxide emissions can be calculated directly from a country's fuel consumption. Emission inventories from industrialized northern countries with reliable energy statistics have relatively small uncertainties, but there is still more guesswork than many care to acknowledge. In developing countries, where data remain sparse and emissions are rising, the numbers are even less reliable.

"We're making silk purses from sows' ears," says Gregg Marland, a scientist with the Energy Department's Carbon Dioxide Information Analysis Center (CDIAC) in Oak Ridge, Tennessee. Even discrepancies of $5-10 \%$ can be significant, as many countries are trying to reduce their emissions by similar magnitudes in the next few years.

One of the best estimates for global carbon emissions comes from CDIAC, which collects 
information from the United Nations, agencies within various countries and industrial organizations to build its own independent inventory. The centre analyses those data to provide more specific information about where and when greenhouse gases were emitted.

CDIAC estimated global carbon dioxide emissions at 30.2 billion tonnes in 2006, not including changes in land use. But Marland says that figure comes with an uncertainty of $6-10 \%$. And the picture gets fuzzier with other gases. The NRC report gave uncertainties ranging from below $25 \%$ to more than $100 \%$ for reported emissions of other greenhouse gases, as well as carbon dioxide from agriculture and other land uses.

In a quest to improve emissions estimates, scientists are pushing governments to expand their monitoring networks. NOAA currently heads a network of some 150 greenhouse-gas monitoring stations around the world, but these stations were originally sited to avoid major pollution sources because scientists at the time were more interested in large-scale trends, rather than in monitoring particular pollution emitters. The agency is now moving in the opposite direction, seeking to expand the network to cover cities, agricultural areas and major industrial sources.

In Europe, scientists are pushing forward with the Integrated Carbon Observation System (ICOS), which aims by 2014 to convert a series of about 50 independent monitoring stations into a single network with uniform monitoring capabilities; it would also add 20 stations to provide finer resolution in key areas. In all, ICOS would cost $€ 150$ million to $€ 200$ million ( $\$ 200$ million to $\$ 266$ million) up front, with operating costs of $€ 25$ million annually.

In California, as part of CalNex, NOAA plans to use aircraft to sample pollution plumes downwind of cities, refineries, power plants and agricultural fields. One target in the Los Angeles area is methane. The state built its inventory for that gas using standard calculations recommended by the Intergovernmental Panel on Climate Change, but a recent sampling study suggests that actual emissions could be one-third higher than estimated.

\section{New tools}

Carbon dioxide is also released by plants and animals, so to gain an accurate picture of the contribution of fossil-fuel burning, researchers are developing new tools to differentiate between 'natural' and fossilfuel carbon in the atmosphere. One technique relies on the radioactive isotope carbon-14, which occurs in trace amounts in atmospheric carbon dioxide.

\section{"If you want to know} if there is a change in emissions from 2010 to 2020, we have to do the measurements now."
This isotope is taken up and released by plants, but fossil fuels have no carbon- 14 because it has a relatively short half-life and they have been buried for millions of years. By taking air samples and measuring their carbon-14 content, researchers can work out how much of the carbon dioxide comes from the biosphere and how much from fossil-fuel emissions.

"If you do this on a large scale, it actually sharpens our view of the biosphere," says Pieter Tans, a senior scientist at NOAA's Earth System Research Laboratory in Boulder.

Levin has been regularly measuring carbon-14 content in air samples from Germany using a version of a Geiger counter, but Tans and other researchers have recently turned to accelerator

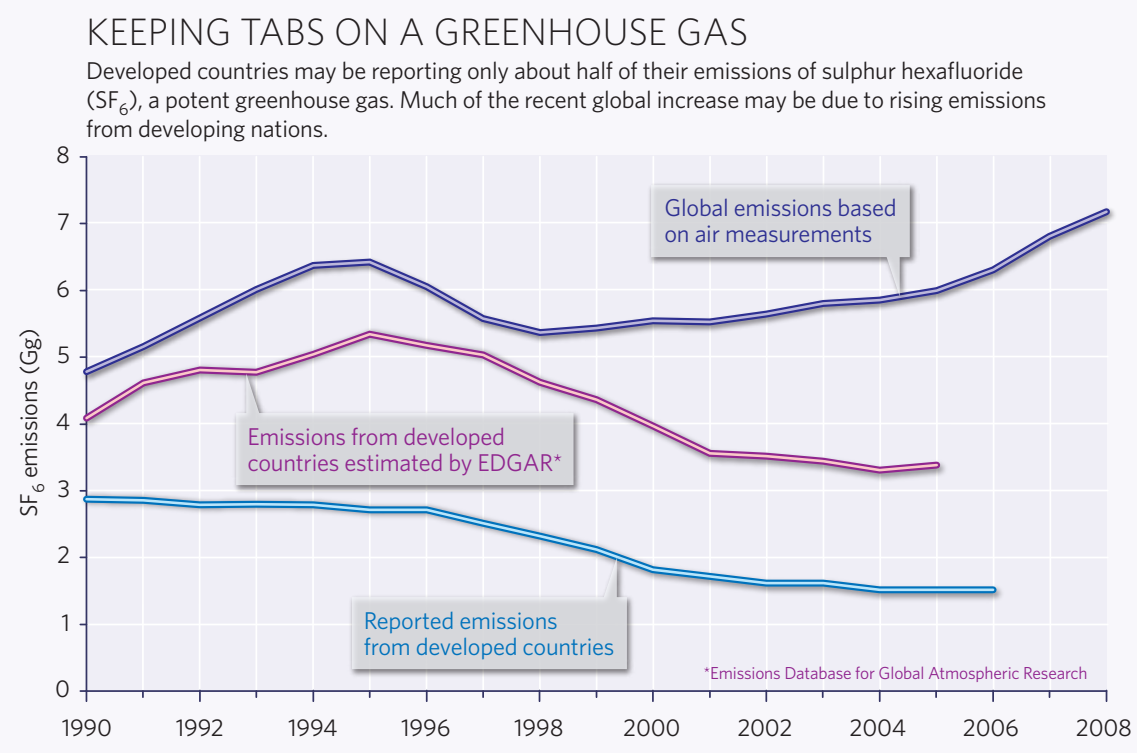

RAIN-MAKING LASERS

mass spectrometry, which is faster and easier to scale up. The NRC committee, which included Tans, recommended ramping up annual carbon-14 measurements to 10,000 worldwide at a cost of $\$ 5$ million to $\$ 10$ million.

Such detailed monitoring should help scientists calibrate measurements from carbon-monitoring satellites. At present, US and Japanese scientists are busy interpreting initial data from a Japanese satellite, and NASA is planning to launch a second version of the Orbiting Carbon Observatory by 2013 (a rocket failure sent the first one hurtling into the Pacific Ocean in February 2009). The French are currently developing another satellite.

Many see satellite measurements as more reliable way to verify greenhousegas emissions. "Everybody can look at the emissions of others in a very transparent way," says Philippe Ciais, who doubles as ICOS coordinator and associate director of the Laboratory for Climate Sciences and the Environment in Gifsur-Yvette, France.

Carbon dioxide monitoring and control will be only one part of any future climate treaty; gases such as methane, nitrous oxide and various fluorine-containing compounds have a powerful warming effect and must be monitored as well. The European Commission and the Netherlands Environmental Assessment Agency have teamed up to create an independent inventory for these lesser greenhouse gases. Called the Emissions Database for Global Atmospheric Research (EDGAR), the inventory collects data from international, national and industrial sources to estimate emissions.

At the University of Heidelberg, Levin used EDGAR's assessment as well as direct measurements taken at 14 locations around the globe to calculate emissions of sulphur hexafluoride $\left(\mathrm{SF}_{6}\right)$, a fireproof insulator used in electrical equipment. A molecule of $\mathrm{SF}_{6}$ has nearly 24,000 times the warming power of a carbon dioxide molecule and remains in the atmosphere for around 3,200 years, which means that essentially all the $\mathrm{SF}_{6}$ ever emitted by humans is still in the atmosphere. Levin's work suggests that $\mathrm{SF}_{6}$ emissions by industrialized countries could be twice as high as those reported to the UNFCCC (see 'Keeping tabs on a greenhouse gas').

Levin says that her finding shows the pitfalls of relying on self-reporting. "If you want to know if there is a change in emissions from 2010 to 2020, we have to do the measurements now, starting in 2010," she says. "I cannot go out today and get air from Heidelberg in September last year. The air is gone."

See Editorial, page 9. 